\title{
PERSON ORGANIZATION FIT, MOTIVASI KERJA, DAN KEPUASAAN KERJA TERHADAP KOMITMEN ORGANISASIONAL
}

\author{
Stefanus Rumangkit ${ }^{1)}$, Jeremiah Haholongan²), \\ email: kit240187@gmail.com, email: holonks@yahoo.com \\ 1), 2 Manajemen, Institut Informatika dan Bisnis Darmajaya \\ Jl. ZA Pagaralam, No 93, Labuhanratu,Bandarlampung
}

\begin{abstract}
Abstrak
Penelitian ini bertujuan untuk mengetahui tingkat komitmen organisasional dan sejauh mana komitmen organisasional dipengaruhi oleh person organization fit, motivasi kerja dan kepuasan kerja. Populasi dalam penelitian ini adalah seluruh dosen tetap dari setiap fakultas yang ada di IIB Darmajaya yaitu sebanyak 91 dosen tetap. Sampel pada penelitian ini menggunakan probability sample. Metode penelitian menggunakan metode assosiatif dengan pendekatan sebab akibat atau kuantitatif. Metode analisis data mengunakan kuisioner dan studi kepustaan (Library research). Alat analisis yang digunakan adalah regresi linear berganda. Hasil penelitian analisis regresi linear berganda diperoleh kesimpulan bahwa komitmen organisasional dipengaruhi oleh person organization fit, motivasi kerja dan kepuasan kerja dan sisanya dipengaruhi oleh faktor atau variabel lainnya. Hasil uji t diperoleh kesimpulan person organization fit tidak berpengaruh terhadap komitmen organisasional. Motivasi kerja berpengaruh positif terhadap komitmen organisasional dan kepuasan kerja berpengaruh positif terhadap komitmen organisasional.
\end{abstract}

Kata Kunci: Person organization fit, Motivasi Kerja, Kepuasan Kerja dan Komitmen Organisasional.

\section{PENDAHULUAN}

Peranan manusia sebagai karyawan dalam perusahaan semakin penting, sehingga mendorong perkembangan ilmu tentang bagaimana mempertahankan karyawan tersebut. Pada era bisnis saat ini perusahaan harus mampu mempertahankan karyawan- karyawan yang berpotensial agar dapat meningkatkan pendapatan perusahaan. Salah satu yang dilakukan dalam mempertahankan karyawannya adalah dengan terus meningkatkan komitmen organisasional. Komitmen organisasional didefinisikan sebagai kekuatan yang bersifat relatif dari individu dalam mengidentifikasikan keterlibatan dirinya kedalam bagian perusahaan, yang dicirikan oleh penerimaan nilai dan tujuan perusahaan, kesediaan berusaha demi perusahaan dan keinginan mempertahankan keanggotaan dalam perusahaan (Robbins dan Judges, 2011).

Komitmen organisasional sangat penting bagi perusahaan untuk menjaga karyawan agar karyawan memberikan kontribusi yang maksimal terhadap perusahaan. Komitmen organisasional merupakan identifikasi rasa, keterlibatan dan loyalitas yang ditunjukan oleh karyawan terhadap perusahaan yang menjadi tempatnya untuk mengabdi dan bekerja hal ini didukung oleh penelitian yang dilakukan oleh Priansa (2016).
Faktor-faktor dari penelitian terdahulu yang dapat mempengaruhi tingkat komitmen organisasional antara lain variabel sosialisasi organisasi, locus of control, budaya organisasi, kinerja, profesional kerja (Rumangkit, 2016; Sanusi. 2012; Taurisa, Ratnawati 2012; Tobing 2009; Tranggono, Kartika 2008). Variabel ini telah diuji sehingga dapat membuat tingkat komitmen organisasional karyawan menjadi lebih tinggi terhadap perusahaan.

Dampak positif dari karyawan yang memiliki komitmen organisasional adalah karyawan akan memiliki komunikasi yang baik sehingga akan ada rasa tanggung jawab untuk mencapai tujuan bersama dan saling membantu antar karyawan. Karyawan yang memiliki komitmen organisasional merupakan hal yang sangat penting dalam menjaga kelangsungan perusahaan. Karena karyawan yang memiliki komitmen organisasional senang untuk menjadi anggota organisasi, percaya terhadap organisasi, maupun perasaan yang baik tentang organisasi, bersedia membela organisasi dan mau melakukan yang baik untuk organisasi serta memberikan seluruh kemampuan yang dimiliki untuk dapat mengerjakan tugasnya dengan baik sehingga perusahaan dapat bersaing dengan kompetitornya.

Komitmen organisasional yang tinggi menjadikan individu peduli dengan nasib organisasi dan berusaha menjadikan organisasi ke arah yang lebih baik, sehingga dengan adanya komitmen yang tinggi kemungkinan terjadinya kesenjangan dapat dihindari. Sebaliknya, individu dengan komitmen rendah akan mementingkan dirinya atau kelompoknya. Dia tidak memiliki keinginan untuk menjadikan organisasi ke arah yang lebih baik hal 
ini didukung oleh penelitian yang dilakukan oleh Hidayat (2014).

Salah satu institusi pendidikan di Lampung yang memiliki tingkat komitmen organisasional tinggi yaitu IIB Darmajaya Lampung. Perguruan tinggi swasta yang bergerak di bidang pendidikan ini telah berdiri sejak tahun 1997 dan masih tetap bertahan hingga saat ini. Perguruan tinggi swasta ini memiliki dua fakultas yaitu ekonomi dan ilmu komputer akan tetapi dibagi lagi menjadi lima jurusan seperti manajemen, akuntansi, teknik informatika, sistem komputer dan sistem informasi.

Sebagai perusahaan yang bergerak dibidang pendidikan banyak sekali tantangan yang dihadapi perusahaan untuk dapat bertahan dalam persaingan saat ini. Banyaknya perguruan tinggi yang ada di kota bandar lampung membuat persaingan dalam bidang pendidikan menjadi lebih tinggi. Salah satu cara perusahaan dalam mengatasi persaingan yang ada yaitu dengan cara meningkatkan komitmen organisasional dari setiap dosen tetap. Komitmen oganisasional dapat disebut juga sebagai perjanjian antara dosen tetap dan perguruan tinggi IIB Darmajaya dimana dosen tetap harus menjalankan visi perguruan tinggi yaitu Tri Dharma Perguruan tinggi dimana perguruan tinggi harus mampu melahirkan dosen-dosen yang memiliki semangat juang yang tinggi dan memiliki pemikiran yang kritis, kreatif, mandiri dan inovatif. Tri Dharma perguruan tinggi terdiri dari tiga point yaitu: Pengajaran memiliki peranan penting dalam suatu proses pembelajaran. Penelitian sangat penting bagi perguruan tinggi, kesejahteraan masyarakat serta kemajuan bangsa dan negara. Pengabdian kepada masyarakat merupakan kegiatan aktivitas akademik yang memanfaatkan ilmu pengetahuan dan teknologi untuk memajukan kesejahteraan masyarakat dan mencerdaskan kehidupan bangsa.

Salah satu dampak positif dari dosen tetap yang berkomitmen dapat ditunjukan dengan grafik masa kerja di dalam organisasi. Dosen yang berkomitmen memiliki kesesuaian tujuan dan keterlibatan dalam organisasi sehingga dosen merasa nyaman dan ingin tetap tinggal di perusahaan tanpa adanya paksaan dari pihak internal maupun eksternal. Penelitian ini di dukung oleh Sumanto (2016) yang mendefiniskan komitmen organisasional adalah kuatnya pengenalan dan keterlibatan seseorang dalam suatu organisasi tertentu.

Penelitian terdahulu yang dilakukan oleh Astuti (2010) dan Tania, Sutanto (2013) menyatakan bahwa komitmen organisasional dipengaruhi oleh person organization fit dan motivasi kerja serta kepuasan kerja. Penelitian yang dilakukan oleh Astusi (2010) dan Tania, Sutanto (2013) pada industri otomotif terdapat kesenjangan. Sehingga pada penelitian yang akan dilakukan peneliti bertujuan untuk menggabungkan variabel person organization fit, motivasi kerja dan kepuasan kerja apakah berpengaruh terhadap komitmen organisasional yang akan di uji pada objek yang berbeda yaitu institusi pendidikan di Kota Bandar Lampung.

Hal yang diduga dapat mempengaruhi komitmen organisasional adalah Person organization fit atau $\mathrm{PO}$ Fit secara luas didefinisikan sebagai kesesuaian antara nilai-nilai organisasi dengan nilai-nilai individu. PO-Fit sangat dibutuhkan dalam menjaga kelangsungan karyawan pada perusahan, apabila karyawan tidak merasakan kesesuaian antara nilai-nilai karyawan dengan perusahaan ditempat karyawan bekerja maka kemungkinan karyawan tersebut akan merasakan ketidaknyamanan dalam bekerja dan bisa menimbulkan keputusan untuk pergi dari perusahaan di tempatnya bekerja saat ini (Kristof, 1996).

Tujuan dari adanya $P O$-Fit bagi perusahaan adalah agar karyawan merasakan tujuan nilai yang sama dengan perusahaan sehingga menimbulkan rasa komitmen organisasional karyawan kepada perusahaan di tempat mereka bekerja. Dampak PO-Fit terhadap komitmen organisasional dapat terjadi jika karyawan merasa kesesuaian antara organisasi dan individu telah terpenuhi seperti organisasi telah memenuhi tanggung jawab terhadap karyawan begitu juga karyawan bertanggung jawab terhadap perusahaan sehingga karyawan akan bekerja secara optimal bagi perusahaan (Mahardika 2006)

Person organization fit dapat mempengaruhi tingkat komitmen organisasional karyawan. Karena semakin merasakan kesesuaian pribadi dengan organisasi maka dengan sendirinya tingkat komitmen organisasional karyawan akan meningkat dan akan bekerja secara optimal di dalam organisasi serta tidak akan memiliki rasa untuk pergi dari perusahaan. Hal di dukung dengan penelitian yang dilakukan oleh Sugianto (2012) yang menyatakan bahwa karyawan yang memiliki kesesuaian dengan organisasi akan terus berada di dalam organisasi sampai jangka waktu yang lama.

Salah satu bentuk cara yang dilakukan perguruan tinggi IIB Darmajaya untuk meningkatkan kesesuaian nilai-nilai organisasi dengan dosen adalah melalui program pro smart seperti profesional yaitu jangan pernah puas dengan kata cukup baik, synergy yaitu hasil yang diperoleh secara bersama akan lebih banyak dibanding hasil saat melakukan sendiri-sendiri, measurable yaitu bekerja tanpa sasaran sama saja dengan berjalan tanpa arah, acceleration yaitu bekerja untuk belajar dan belajar untuk kemajuan, responsibility yaitu bertanggung jawab atas pilihan dan bebas untuk memilih, trustworthy yaitu kemukakan kebenaran sesuai fakta. Program pro smart diberikan kepada dosen melalui berbagai cara seperti membuat mading mengenai pro smart di setiap gedung yang ada di perguruan tinggi IIB Darmajaya agar dosen tetap dapat selalu memahami kesesuaian nilai-nilai antara organisasi dan dosen tetep. Selain melalui madding pro smart juga diberikan melalui kegiatan coffe morning yang menjelaskan tentang kebijakan akademik, pembacaan surat 
keputusan rolling karyawan, pengenalan karyawan baru. Pada setiap kegiatan coffe morning dihadiri oleh kusdm, rektor, jajaran karyawan dengan cara ini kampus dapat meningkatkan rasa komitmen organisasional dari dosen. Data ini diperoleh langsung dari kampus IIB Darmajaya Lampung.

Selain PO-Fit faktor lain yang mempengaruhi komitmen organisasional adalah motivasi. Motivasi kerja juga merupakan kondisi yang menggerakan diri karyawan agar terarah atau tertuju untuk mencapai tujuan organisasi perusahaan. Jadi motivasi kerja dapat diartikan sebagai semangat kerja yang ada pada karyawan yang membuat karyawan tersebut dapat bekerja untuk mencapai tujuan tertentu (George and Jones, 2005). Maka dapat disimpulkan bahwa motivasi merupakan dorongan yang dapat membangkitkan kemauan kerja seorang dosen untuk melaksanakan pekerjaan yang sesuai dengan tugas dan tanggung jawabnya. Keberhasilan suatu perusahaan sangat tergantung pada kemampuan perusahaan dalam mengelola sumber daya manusia yang dimiliki.

Hal tersebut menuntut perusahaan memberikan motivasi yang sesuai dengan tujuan untuk membangkitkan semangat dosen dalam lingkungan kerja demi tercapainya tujuan dan kesuksesan perusahaan. Karyawan yang termotivasi dapat mempengaruhi rekan kerjanya untuk berlaku sama dengan apa yang ia lakukan kepada perusahaannya, sehingga perusahaan akan mencapai keberhasilan (Wardhani, Susilo dan Iqbal, 2015). Salah satu hal yang dilakukan perguruan tinggi IIB Darmajaya dalam memotivasi dosen tetap yaitu dengan memberikan pelatihan- pelatihan kepada dosen seperti: Workshop Nasional 2017 "Teknik Merancang \& Melakukan Penelitian Eksperimen", Sosialisasi Studi Lanjut UKM, Certificate In Teaching Auditing (CTA), Training Brevet Pajak, Training Oracle Academy. Selain melalui pelatihan untuk meningkatkan motivasi dosen yaitu dengan system pemberian apresiasi seperti pengakuan dari atasan maupun rekan kerja saat dosen tetap mampu menyelesaikan hasil kerja yang diberikan oleh perguruan tinggi IIB Darmajaya dengan baik dan sesuai waktu yang telah ditentukan tanpa ada kesalahan. Data ini diperoleh langsung dari perguruan tinggi IIB Darmajaya Lampung.

Selain $\mathrm{PO}$-Fit dan motivasi ada faktor lain juga yang mempengaruhi komitmen organisasional yaitu kepuasan kerja. Kepuasan kerja dapat mempengaruhi tingkat komitmen organisasional karyawan. Karyawan yang merasakan kepuasan dalam bekerja dapat dilihat melalui pekerjaan yang mampu diselesaikan tanpa ada tuntutan yang mendesak sehingga dosen tetap merasa pekerjaan yang dilakukan sangat menarik dan diberikan kebebasan seluas-luasnya dalam bekerja. Hal ini akan membuat kepuasan kerja karyawan serta dengan sendirinya membuat karyawan yang ada betah berada di dalam perusahaan serta timbul rasa komitmen organisasional yang tinggi. Ketika di dalam sebuah perusahaan karyawan yang satu dengan yang lain saling mendorong dan membantu dalam melakukan pekerjaan yang sulit maka karyawan tersebut juga akan merasa nyam berada di dalam perusahaan. Ketika karyawan sudah merasa nyaman maka akan bekerja secara optimal dan tidak akan memiliki rasa untuk pergi dari dalam perusahaan meskipun beban kerja yang diberikan terlalu berat. Hal ini didukung oleh penelitian yang dilakukan oleh Sailendra dan Wibasuri (2014) yang menyatakan bahwa karyawan pada umumnya berharap bahwa kepuasan kerja yang diterimanya dapat memenuhi kebutuhannya.

Menurut Hasibuan (2016, p.202) kepuasan kerja adalah sikap emosional yang menyenangi dan mencintai pekerjaannya. Perusahaan yang bergerak di bidang jasa pendidikan harus dapat memenuhi kebutuhan dosen sehingga dosen merasa puas dan memiliki komitmen organisasional yang tinggi. Karyawan yang memiliki kepuasan dalam bekerja akan menciptakan komitmen organisasional, sehingga tujuan perusahaan dapat tercapai karena hal ini didukung penuh oleh karyawan terutama dosen tetap. Dosen yang merasa puas dengan pekerjaannya, maka karyawan akan melaksanakan tugas pada tingkat yang lebih tinggi dibandingkan dengan karyawan yang kurang puas, Hartatik (2014, p.222).

Kepuasan kerja yang tidak optimal akan dapat menimbulkan rasa ingin pergi dari tempat karyawan bekerja saat ini berbeda dengan sebaliknya bila karyawan merasakan kepuasan dalam bekerja maka karyawan akan berkomitmen pada organisasi. Dampak dari adanya kepuasa kerja karyawan pada organisasi adalah dengan kemajuan-kemajuan yang terlihat pada organisasi seperti meningkatnya perusahaan, optimalnya pekerjaan yang dilakukan karyawan, konsekuensi karyawan terhadap perusahaan. Secara sederhana kepuasan kerja atau job satisfaction dapat disimpulkan sebagai apa yang membuat seseorang menyenangi pekerjaan, sehingga dilakukan karena mereka merasa senang dan tidak terbebani oleh pekerjaan. Lutfie (2014) menemukan bahwa komitmen organisasi dipengaruhi oleh kepuasan kerja. Penelitian lain Puspitawati, Dwi dan Riana (2014) menemukan bahwa kepuasan kerja berpengaruh terhadap komitmen organisasional.

\section{PEMBAHASAN}

Secara keseluruhan total kuesioner yang didistribusikan berjumlah 91 kuesioner. Pengukuran person-organization fit mengadopsi alat ukur yang dikembangkan oleh Kristof (1996). Alat ukur komitmen organsasional mengadopsi alat ukur yang dikembangkan oleh Mowday et al (1979) dengan 15 pertanyaan. Kepuasaan kerja diukur job descriptive index (JDI) dengan 5 pertanyaan. Sedangkan, motivasi kerja diukur dengan WEIMS (work extrinsic and intrisic motivation scale) yang 
dikembangkan oleh Tremblay et al (2009). Pengambilan data dilakukan pada bulan juni-juli 2017. Secara umum, mayoritas responden adalah Pria (50 orang atau 54.9\%) dengan usia kisaran 31 - 40 tahun keatas dengan masa kerja lebih dari 5 tahun (67 dosen).

Dari hasil uji validitas dengan menggunakan uji koefisien korelasi produk moment, 35 butir pertanyaan dinyatakan valid. Selanjutnya untuk uji reliabilitas dengan menggunakan uji cronbach's alpha menunjukkan variabel person organization fit memiliki tingkat reliabilitas paling tinggi dengan $\mathrm{a}=0,756$, diikuti dengan variabel komitmen organisasional dengan $\mathrm{a}=0,752$, kemudian variabel kepuasan kerja dengan $a=0,748$, dan variabel motivasi kerja $\mathrm{a}=0,731$.

\section{Tabel 1. Analisis Regresi Berganda}

\begin{tabular}{|c|c|c|c|c|c|}
\hline \multirow[t]{2}{*}{ Model } & & \multicolumn{2}{|c|}{$\begin{array}{l}\text { Unstandardized } \\
\text { Coefficients }\end{array}$} & \multirow[t]{2}{*}{$\mathrm{t}$} & \multirow[t]{2}{*}{ Sig. } \\
\hline & & B & Std. Error & & \\
\hline \multirow{4}{*}{1} & (Constant) & -.588 & 2.449 & -.240 & .811 \\
\hline & $\mathrm{X} 1$ & .080 & .078 & 1.033 & .304 \\
\hline & $\mathrm{X} 2$ & .235 & .085 & 2.775 & .007 \\
\hline & X3 & .387 & .075 & 5.154 & .000 \\
\hline
\end{tabular}

Berdasarkan hasil analisis regresi berganda, maka : a) Konstanta a sebesar 0.588 menyatakan bahwa komitmen organisasional pada dosen tetap perguruan tinggi IIB Darmajaya Lampung adalah sebesar 0.588 apabila person organization fit, motivasi kerja dan kepuasan kerja bernilai $=0$. b) Koefisien regresi untuk X1 $=0.080$ menyatakan bahwa setiap penambahan person organization fit maka akan meningkatkan komitmen organisasional pada dosen tetap IIB Darmajaya Lampung sebesar 8\%. c) Koefisien regresi untuk X2 $=0.235$ menyatakan bahwa setiap penambahan motivasi kerja maka akan meningkatkan komitmen organisasional pada dosen tetap IIB Darmajaya Lampung sebesar 23.5\%. d) Koefisien regresi untuk X3 $=0.387$ menyatakan bahwa setiap penambahan kepuasan kerja maka akan meningkatkan komitmen organisasional pada dosen tetap IIB Darmajaya Lampung sebesar 38.7\%.

Nilai koefisien korelasi (R) dalam penelitian ini sebesar 0.771 artinya tingkat hubungan antara person organization fit (X1), motivasi kerja (X2) dan kepuasan kerja (X3) dengan komitmen organisasional (Y) adalah positif kuat. Koefisien determinan R2 ( $\left.R_{\text {Square }}\right)$ sebesar 0.594 artinya bahwa komitmen organisasional dipengaruhi oleh person organization fit (X1), motivasi kerja (X2) dan kepuasan kerja (X3) sebesar 0.594 atau $59.4 \%$. Sedangkan sisanya sebesar $40.6 \%$ dipengaruhi oleh faktor atau variabel lain diluar penelitian ini.

Tabel 2. Hasil Uji T

\begin{tabular}{|l|l|l|l|}
\hline VARIABEL & t-hitung & t-tabel & KETERANGAN \\
\hline
\end{tabular}

\begin{tabular}{|l|c|c|c|}
\hline $\begin{array}{l}\text { Person } \\
\text { Organization } \\
\text { Fit }\end{array}$ & 1.033 & 1.662 & $\begin{array}{l}\text { Tidak } \\
\text { Terdukung }\end{array}$ \\
\hline $\begin{array}{l}\text { Motivasi } \\
\text { Kerja }\end{array}$ & 2.775 & 1.662 & Terdukung \\
\hline $\begin{array}{l}\text { Kepuasaan } \\
\text { Kerja }\end{array}$ & 5.154 & 1.662 & Terdukung \\
\hline
\end{tabular}

Sumber: diolah tahun 2017

Tabel 3. Hasil Uji F

\begin{tabular}{|l|c|c|c|}
\hline f-hitung & F tabel & Signifikansi & KETERANGAN \\
\hline 42.488 & 3.1000 & 0.000 & $\begin{array}{c}\text { Hipotesis } \\
\text { Terdukung }\end{array}$ \\
\hline
\end{tabular}

Sumber : diolah tahun 2017

Pengujian hipotesis pertama menunjukkan bahwa variabel person organization fit tidak mempunyai pengaruh terhadap komitmen organisasional. Tidak berpengaruhnya variabel ini tidak akan merubah tingkat komitmen dosen tetap di IIB Darmajaya, karena ada atau tidak adanya kesamaan nilai-nilai antara organisasi dengan dosen tetap tidak akan berpengaruh kepada tingkat komitmen organisasional. Hal ini disebabkan oleh adanya faktor-faktor lain seperti sosialisasi organisasi, locus of control, budaya organisasi, kinerja, professional kerja yang dapat menyebabkan dosen lain untuk berkomitmen kepada perguruan tinggi IIB Darmajaya. Hasil penelitian bertolak belakang dengan temuan dari Sugianto (2012) dan M. Rawung (2014) yang menyatakan person organization fit berpengaruh positif dan signifikan terhadap komitmen organisasional. Hipotesis pertama (H1) dalam penelitian ini ditolak.

Pengujian hipotesis kedua menunjukkan bahwa motivasi kerja berpengaruh terhadap komitmen organisasional. Motivasi kerja dalam diri manusia dapat berupa motivasi internal diri dan eksternal. Motivasi internal diri merupakan motivasi yang muncul dari dalam pikiran, hati dan keinginan diri sendiri. Motivasi eksternal merupakan motivasi yang muncul karena adanya dorongan dari luar pribadi, misalnya dari orang lain dan organisasi tempat bekerja. Semakin tinggi tingkat motivasi yang diberikan kepada setiap dosen tetap terhadap pekerjaannya, maka semakin tinggi pula komitmen organisasional yang diberikan dosen tetap terhadap perguruan tinggi IIB Darmajaya. Dosen tetap dapat merasa termotivasi apabila pihak IIB Darmajaya telah mampu memenuhi kebutuhan dosen tetap seperti pemberian pelatihan, pemberian kenaikan pangkat sesuai prestasi kerja yang telah dilakukan dan rekan kerja, atasan memberi pengakuan atas pekerjaan yg telah diselesaikan dengan baik. Oleh karena pihak perguruan tinggi telah memberikan motivasi yang baik maka dosen tetap akan berkomitmen kepada organisasi dengan sendirinya. Hasil penelitian ini mendukung dari penelitian terdahulu Lestari (2016) yang 
menyatakan bahwa motivasi kerja berpengaruh positif terhadap komitmen organisasional. Apabila atasan memiliki motivasi kerja yang tinggi maka komitmen dalam menjalankan pekerjaannya juga akan meningkat. Nurlaely (2016) yang menyatakan bahwa ada pengaruh positif dan signifikan antara motivasi kerja terhadap variabel terikat yaitu komitmen organisasional. Hipotesis kedua $(\mathrm{H} 2)$ dalam penelitian ini diterima.

Pengujian hipotesis ketiga menunjukkan bahwa kepuasan kerja berpengaruh terhadap komitmen organisasional. Kepuasan kerja merupakan sikap umum seseorang dalam menghadapi pekerjaannya. Seseorang yang tinggi kepuasan kerjanya memiliki sikap positif terhadap pekerjaannya, sedangkan seseorang yang tidak memperoleh kepuasan didalam pekerjaannya memiliki sikap yang negative terhadap pekerjaannya. Pengujian hipotesis ketiga menunjukkan bahwa kepuasan kerja berpengaruh terhadap komitmen organisasional. Kepuasan kerja merupakan sikap umum seseorang dalam menghadapi pekerjaannya. Seseorang yang tinggi kepuasan kerjanya memiliki sikap positif terhadap pekerjaannya, sedangkan seseorang yang tidak memperoleh kepuasan didalam pekerjaannya memiliki sikap yang negative terhadap pekerjaannya.

Pengujian hipotesis ketiga menunjukkan bahwa kepuasan kerja berpengaruh terhadap komitmen organisasional. Kepuasan kerja merupakan sikap umum seseorang dalam menghadapi pekerjaannya. Seseorang yang tinggi kepuasan kerjanya memiliki sikap positif terhadap pekerjaannya, sedangkan seseorang yang tidak memperoleh kepuasan didalam pekerjaannya memiliki sikap yang negative terhadap pekerjaannya.

\section{KESIMPULAN}

Berdasarkan analisis dan pengujian hipotesis maka simpulan dalam penelitian ini, yaitu: 1) Person organization fit tidak berpengaruh terhadap komitmen organisasional, 2) motivasi kerja berpengaruh terhadap komitmen organisasional, 3) kepuasaan kerja berpengaruh terhadap komitmen organisasional. 4) person organization fit, motivasi kerja, dan kepuasaan kerja berpengaruh secara bersama-sama terhadap komitmen organisasional.

\section{DAFTAR PUSTAKA}

[1]. Apriyanti (2016). Pengaruh Kompensasi dan Kepuasan Kerja terhadap Komitmen Pegawai. Jurnal JIBEKA Volume 10 No. 1.

[2]. Astuti, S (2010). Model Person- Organization Fit (P-O FIT MODEL) terhadap Komitmen Organisasional. Jurnal Bisnis dan Ekonomi (JBE) Vol. 17, No. 1 ISSN: 1412312643.
[3]. Aurty, C.W and Daugherty P.J (2003). Warehouse Operation Employees: Linking Person- Organization Fit, Job Satisfaction and Coping Response, Journal of Business Logistic, Volume 24 No. 1.

[4]. Edison, Emron, dkk (2016) Manajemen Sumber Daya Manusia. Alfabeta. Bandung.

[5]. George, J.M. \& Jones, G.R. (2005). Understanding and managing organizational behavior (4th ed.). New Jersey: Upper Saddle River.

[6]. Hartatik, Indah Puji (2014) Buku Praktis Mengembangkan SDM. Laksana. Jogjakarta.

[7]. Hasibuan, Malayu S.P (2016). Manajemen Sumber Daya Manusia. Bumi Aksara. Jakarta.

[8]. Hidayat (2014). Faktor-faktor Komitmen Organisasional serta pengaruh terhadap Organizational Citizenship Behavior. Jurnal NeO-Bis Volume 8 No. 1.

[9]. Januri, Bambang Satriawan (2007) "Pengaruh Kepuasan Kerja, Budaya Organisasi, dan jabatan Terhadap Komitmen Organisaional". Riset Akuntansi dan Bisnis. Vol 7 No 2. Hal 139-159.

[10]. Kristof, A. L. (1996). Person-organization fit: an Integrative Review of its Conceptualizations Measurement, and Implications. Personnel Psychology 49, 1-49.

[11]. Kusmaningtyas (2012). Kajian Teori Model Seleksi Karyawan (Person-Organization Fit Model dan Competence Model). Jurnal Ekonomika Volume 5 No. 1. Hal 17-23.

[12]. Lestari (2016). Kepuasan Kerja dan Motivasi terhadap Komitmen Organisasi. SOSIO-EKONS Vol 8 No. 1.

[13]. Lutfie (2014). The Effect of The Work- Family Conflict and Employee's Job Satisfaction Towards the Organization Commitment. Jurnal Siasat Bisnis Volume 18 No. 2.

[14]. Mangkunegara A.P (2011). Manajemen Sumber Daya Manusia Perusahaan. Rosdakarya. Bandung.

[15]. Nurlaely, Riani (2016). Pengaruh Diplin Kerja, Motivasi Kerja, Kepuasan Kerja dan Kompetensi terhadap Komitmen Organisai. Jurnal Ekonomi Sumber Daya Vol 18 No.1

[16]. Ocataviani, Hartijasti (2016). Pengaruh Person Organization Fit dan Budaya Organisasi terhadap Turnover Intention dengan kepuasan 
Kerja sebagai variabel Mediator. Jurnal Manajemen Indonesia Volume 16 No. 1.

[17]. Oka I.G (2015). Person Organization Fit, Kepuasan kerja, Komitmen Organisasi, Organizational Citizenship Behaviour dan Kinerja karyawan. ISSN: 1892-8486, Volume 12 No. 1.

[18]. Priansa, Donni Juni. (2016) Perencanaan dan Pengembangan Sumber Daya Manusia. Alfabeta. Bandung.

[19]. Puspasari, Durinda dan Alfiana, Zakiah Mufida. (2013). "Pengaruh Budaya Organisasi terhadap Komitmen Organisasi". Universitas Negeri Surabaya. Hal 1-19.

[20]. Puspitawati, Ni made dwi dan Riana, I Gede (2014) "Pengaruh Kepuasan Kerja Terhadap Komitmen Organisasional dan Kualitas Layanan". Manajemen Strategi Bisnis dan Kewirausahaan. Vol 8 No 1.

[21]. Rawung. (2012). Pengaruh Person Organization Fit dan Karakteristik individu terhadap Komitmen Organisasi. Vol 2 No. 1.

[22]. Rumangkit, S. (2016). Pengaruh Sosialisasi Organisasi Pada Komitmen Afektif Yang Dimediasi Oleh Kesesuaian Nilai. Jurnal Bisnis Darmajaya, 2(1), 34-56.

[23]. Salemdra, Wibasuri (2014). Faktor-Faktor Lingkungan Kerja dan Kepuasan Kerja yang Berpengaruh terhadap Loyalitas Kerja Karyawan PT. MEGA AUTO CENTRAL FINACE LAMPUNG SELATAN. Jurnal Portofolio Volume 11 No. 1.

[24]. Salim, Agus (2013) "Pengaruh Kepuasan Kerja Terhadap Komitmen Organisasional, kinerja, dan Turnover intention". Hal 1-7.

[25]. Sanusi (2012). Organisasi dan Komitmen Locus of Control atas Partisipasi Penyusutan Estimasi terhadap Kinerja. JMK Volume 10 No. 1.

[26]. Sekiguchi (2004). Person Organization Fit and Person Job Fit in Employee Selection: A Review of The Literature. Osaka Keidai Ronshu Vol. 54 No. 6.

[27]. Suarjana (2016). Pengaruh Motivasi Kerja dan Kepuasan Kerja terhadap Komitmen Organisasi. Jurnal Bisnis dan Kewirausahaan Vol 12 No.1.

[28]. Sugianto, Thoyib Noermijati (2012). Person Organization Fit, Motivasi. Kepuasan terhadap komitmen organisasi. Jurnal Aplikasi Manajemen Volume 10 No 2.
[29]. Sugiyono (2016). Metode penelitian Bisnis dan Statistika untuk penelitian. Alfabeta. Bandung.

[30]. Sumanto, Herminingsih (2016). Pengaruh Budaya Organisasi dan Motivasi Kerja terhadap Komitmen Organisasional. Jurnal Ilmiah Manajemen dan Bisnis Volume 2 No.1.

[31]. Tania, A \& Sutanto, E (2013). Pengaruh Motivasi kerja dan Kepuaasan kerja terhadap Komitmen Organisasional karyawan. Agora Vol. 1, No. 3, Universitas Kristen Petra, Surabaya.

[32]. Taurisa, Ratnawati (2012). Analisis Pengaruh Budaya Organisasi dan Kepuasan Kerja terhadap Komitmen Organisasional dalam meningkatkan Kinerja Karyawan. Jurnal Bisnid dan Ekonomi Volume 19 No. 2.

[33]. Tobing (2009). Pengaruh Komitmen Organisasional dan Kepuasan kerja terhadap Kinerja Karyawan. Jurnal Manajemen dan Kewirausahaan Volume 11 No. 1.

[34]. Tranggono, Kartika (2008). Pengaruh Komitmen Organisasional dan Profesional terhadap Kepuasan Kerja Auditor dengan Motivasi sebagai variabel Intervening.

[35]. Wardhani, Susilo Iqbal (2015). Pengaruh Motivasi Kerja Karyawan terhadap Komitmen Organisasional dengan Kepuaan Kerja sebagai Variabel Intervening. Jurnal Administrasi Bisnis (JAB) Vol 2 No. 1.

[36]. Wibowo (2015) Prilaku Dalam Organisasi. Rajagrafindo Persada. Depok.

[37]. Widiarti, Dewi (2016). Pengaruh Iklim Organisasi dan Kepuasan Kerja terhadap Komitmen Organisasional. E-Jurnal Manajemen Unud Volume 5 No. 10.

[38]. Widodo (2010). Analisis Pengaruh Keamanan Kerja dan Komitmen Organisasional terhadap Turnover Intention Serta Dampaknya pada Kinerja Karyawan Outsourcing. Universitas Diponogoro.

[39]. Yudha (2014). Pengaruh Motivasi terhadap Komitmen Organisasional. JESTT Volume 1 No. 5. 